\title{
Intelligent Models of Long-Term Security Correction in Energy Conversion Dispatching
}

\author{
Chaochun Luo ${ }^{1}$, Dunnan Liu ${ }^{2}$, Qingqi Chen ${ }^{1}$, Xinming Liu ${ }^{2}$ \\ ${ }^{1}$ Power Exchange Center, Hunan Electric Power Company, Changsha, China \\ ${ }^{2}$ School of Economics and Management, North China Electric Power University \\ Email: chchluo@163.com, liudunnan@163.com, chenqq@ hnepc.com.cn
}

Received January, 2013

\begin{abstract}
This paper is research on the dispatching models for monthly generation plan which is manage the congestion considering the security constrains of the power grid. Since the monthly generation plan is the result of vary monthly power exchange, including long-term power contract, power exchange among provinces and generation constitution exchanges, The application of monthly security constrained dispatching is with significant meaning for the security and stability of power grid. This paper brings forward the purpose and contents of security dispatching and introduces the working procedure and mathematic models. At last, the practical example of the Hunan Province power grid is introduced to explain the models.
\end{abstract}

Keywords: Intelligent Models; Congestion Management; Electricity Market; Monthly Generation Plan

\section{Introduction}

In recent years, environmental protection and climate change have become the world's most important issue of common concern. Energy conservation, the improvement of energy efficiency and the development of renewable energy sources have become the basic energy policies. China's "Eleventh Five-Year Plan" made it clears that to the year 2010 the energy consumption of unit GDP and total emissions of major pollutants will reduce by $20 \%$ and 10\%.respectively compared to the year 2005 .

The power industry is the key area of energy saving and pollution reduction with great energy-saving potential. In view of this, the National Development and Reform Commission formulated the "energy generation scheduling (Trial)[1], and has submitted it to the State Council for approval in early 2007. In June of 2007, with "on energy conservation scheduling the implementation of alternative electricity generation guidance" issued by Economic and Trade Commission of Hunan Province[2], Hunan Electric Power Company developed the "Hunan power grid to carry out energy-saving scheduling implementation details the implementation of alternative electricity generation", to achieve the goals of energy-saving and emission reduction through the market-oriented means.

Middle and long-term energy security checking is an important guarantee for the Implementation of generation energy-saving scheduling. The scheduling of Hunan Province needs to consider the power generation capacity of plants, peaking capacity, safe operation of power network, net loss and other factors, determine whether the transaction of alternative power generation is effective, and is responsible for the implementation of effective transaction of alternative power generation. Middle and long-term security checking refers to the security constraint adjustments in terms of power plans, and its main function is to test and adjust the plans of monthly electricity consumption, so as to meet inter-regional security constraints, where the monthly electricity consumption includes annual contracts decomposed to every month, contracts of external transmitting power and bidding power of alternative generation. The implementation and operation of middle-long term security checking is essential to ensure the safety operation of power network and improve the enforceability of power plans $[3,4]$.

In view of the characteristics of monthly power including wide time span and strong uncertainty, this paper will use the tie-line stability limit of the average family as the security constraints between areas. To present processes and algorithms of middle-long tern security checking under energy generation scheduling model to verify the actual network data.

\section{The Main Transaction Process}

In order to better describe the relative functions of the middle-long term security checking, it is necessary to introduce the transaction process of alternative generation and power bidding rules briefly. Alternative power 
generation refers to trading tools to promote the substitution of low-capacity and high-energy generating units for generating units with high capacity and high energy efficiency, to achieve energy saving and emission reduction through the market-oriented means. The main transaction process is as follows:

1) Electricity Trading Center releases the centralized transaction reporting notification about monthly alternative power on 16th of each month, and clarifies trading days.

2) Before 17:00 in the first 2 working days of trading days, the power Trading Center releases the next month's monthly pre-power projects of trading unit, and trading unit involved in alternative power generation focused on transactions monthly maximum transfer/transferee power of monthly alternative power centralized transaction.

3) Trading subjects participating in the centralized transactions of monthly alternative power generation confirm the transferors/transferees' status through technical support systems of alternative power generation transactions to the power grid electricity trading center in Hunan, and submit the transaction declarations from 9:00pm in the trading day; 9: 00-12:00 am in the trading day is a free reporting period; 12:00 in the trading day is a deadline for reporting, and technical support system will match the clearing according to the final effective transaction declarations.

4) The power trading center will hand over the preliminary results of monthly alternative power generation centralized transaction to Hunan Electric Power Dispatching and Communication Center before 17:00 in the transaction day.

5) Dispatching and Communication Center will complete the safety check of the transaction preliminary results, and feedback the checking suggestions to the electricity trading center before 17: 00 in the third working days after the transaction day.

6) The power trading center will make the necessary adjustments for the preliminary results of the transaction, until the security check is passed and the centralized trading results of monthly alternative power generation is formed. Additionally, the power trading center power generation releases and issues transaction notice to the relevant transaction subjects through technical support systems about alternative power generation trading before 17:00 in the fourth working day after the trading days.

7) Dispatch communications center is responsible for the implementation of centralized trading results of monthly alternative power generation.

\section{The Main Process of Security Checking}

According to the orders about security and stability and existing scheduling and running system, on the basis of the appropriate partition of the entire power grid and the formation of multiple independent security zones, security checking software regards the average stable limits of the contact line as constraints to test and adjust the monthly power plan, so as to meet the needs of security and stability of inter-regional power transmission. Figure 1 shows the basic model of the middle-long term safety checking, the power grid by consists of two safety zones labeled by $\mathrm{A}$ and $\mathrm{B}$, contact line is denoted with $\mathrm{T}$.

According to the power balance relationship after safety partition of A zone, the flow of contact line $\mathrm{T}$ can be calculated by the following formula:

$$
W_{\mathrm{T}}=\sum_{t=1}^{N_{t}} W_{t}^{\mathrm{A}}=\sum_{g=1}^{N_{g}} W_{g}^{\mathrm{A}}-\sum_{l=1}^{N_{l}} W_{l}^{\mathrm{A}}
$$

where $W_{g}$ denotes the monthly planning power of unit g; $W_{t}$ dentes the flow of contact line t; $W_{l}$ denotes load capacity of the month; $N_{g}$ represents the total number of units; $N_{t}$ represents the number of contact lines, $N_{l}$ represents the number of load nodes.

Similarly, the following formula can be obtained from the power balance of zone B:

$$
W_{\mathrm{T}}=-\sum_{t=1}^{N_{t}} W_{\mathrm{t}}^{\mathrm{B}}=\sum_{l=1}^{N_{l}} W_{l}^{\mathrm{B}}-\sum_{g=1}^{N_{g}} W_{g}^{\mathrm{B}}
$$

with the consideration of the upper and lower space of generation output of each partition, and the flow constraints of contact line groups, the amount of planning power adjustments can be expressed in the following formula:

$$
\mathrm{d} W^{\mathrm{A}}=\left\{\begin{array}{cc}
-\min \left\{\left(W_{T}-W_{T, \max }\right), S_{\mathrm{A}}^{-}, S_{\mathrm{B}}^{+}\right\}, & W_{T}>W_{T, \max } \\
\min \left\{\left(W_{T, \min }-W_{T}\right), S_{\mathrm{A}}^{+}, S_{\mathrm{B}}^{-}\right\}, & W_{T, \min }>W_{T}
\end{array}\right.
$$

where $\mathrm{d} W^{\mathrm{A}}$ is the adjusting amount of planning power of zone $\mathrm{A} ; \mathrm{d} W^{\mathrm{B}}$ is the amount of power adjustments; $W_{\mathrm{T}}$ is the flow of contact line groups; $W_{T \text {,max }}$ is the upper flow limits multiplied by upper stable limits of contact line groups, the average load rate and adequacy factors; $W_{T \text {,min }}$ is the lower flow limits multiplied by lower stable limits of contact line groups, the average load rate and adequacy factors; the up-regulated space of security zone $S_{\mathrm{A}}^{+}, S_{\mathrm{B}}^{+}$refers to the increased power with the biggest possibility of generation plants within

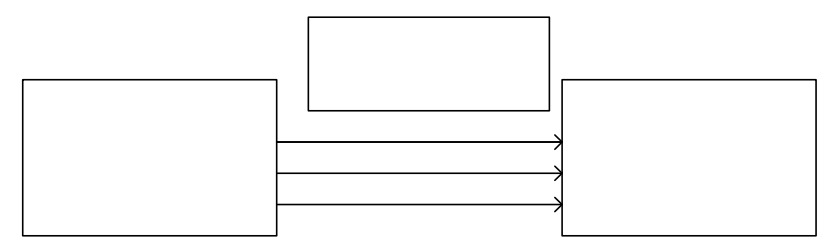

Figure 1. The basic model of the middle-long term safety checking. 
the security zone; the down-regulated space of security zone $S_{\mathrm{A}}^{-}, S_{\mathrm{B}}^{-}$refers to the decreased power with the biggest possibility of generation plants within the security zone. We take zone $\mathrm{A}$ as example, and present the calculating formulas as follows:

$$
\begin{aligned}
& S_{\mathrm{A}}^{+}=\sum_{g=1,}^{N_{g}}\left(W_{g, \operatorname{A}, \mathrm{Ax}}^{\mathrm{A}}-W_{g}^{\mathrm{A}}\right) \\
& S_{\mathrm{A}}^{-}=\sum_{g=1, g \in \mathrm{A}}^{N_{g}}\left(W_{g}^{\mathrm{A}}-W_{g, \min }^{\mathrm{A}}\right)
\end{aligned}
$$

where $W_{g, \text { max }}^{\mathrm{A}}, W_{g, \text { min }}^{\mathrm{A}}$ represents the maximal and minimal power respectively.

In summary, middle-long term safety checking includes the following processes [4,5]:

1) Reading and pre-processing the raw data of trading center.

2) According to actual operation situations of power network and protocols for security and stability security zone partition is made.

3) The upper and lower flow limits of contact line groups are calculated from stable limits.

4) Carry out power balance from (1) and (2) partition.

5) Calculating the flow cross-border situation of contact line groups.

6) With the consideration of generation capacity, the flow cross-border situation, the net losses and other factors, proposing some adjusting suggestions and feeding them back to the trading center.

\section{Case Analysis}

\subsection{Safety Division of Hunan Power Grid}

The indices to reflect the generators' status in the market can be obtained by comparing the capacity of different market suppliers and the market demand. Many indices in this class, such as RSI [2, 3] and MRR [4] have been studied by many researchers. Here we introduce two representative indices.

1) After years of construction, Hunan power grid has built the main grid with $500 \mathrm{kV}$ lines and the regional backbone grid with $220 \mathrm{kV}$ lines connected through 500 $\mathrm{kV}$ back lines with the Eastern grid. Among them, the Huai River coal bases concentrate $56.1 \%$ generating capacity of the main power plants of the whole province, the rest of the main thermal power plants are distributed along the area of Yangtze River. As part of Eastern power grid and an important energy-output province of East China Power Grid, Hunan power grid ensures its own electricity supply and bears the important task of transmitting electricity to economically developed areas.

2) According to the characteristics of geographical distribution of Hunan power grid and procedures of stability and security, Hunan power grid can be divided into
A, B, C, D, E, F, G, H, I, a total of nine security partitions, each partition contains a certain amount of generating units and system load, the topology connection is shown in Figure 2.

\subsection{The Adjusting Processes of Monthly Power Transactions}

Let's take zone A of Hunan power grid for example, carry out for a comprehensive validation for middle-long term safety checking algorithms, and ultimately give the adjusting effects of middle-long term security checking under the modes of energy scheduling. In July 2008, according to the given definition of safety area and contact line groups, we follow the idea of zoning regulations to give the power balance plan of zone A before adjustments, Table 1.

Through the power balance to generating capacity, the total load, the upper flow limit of contacting line groups we can see that, the planned trading power of area $\mathrm{A}$ is too high, and the monthly planned generation is far greater than the sum of total power generation capacity and the contact line groups. The actual implementation has some difficulties. Table 2 shows the adjusted balance of power balance plans of area A after adjustments.

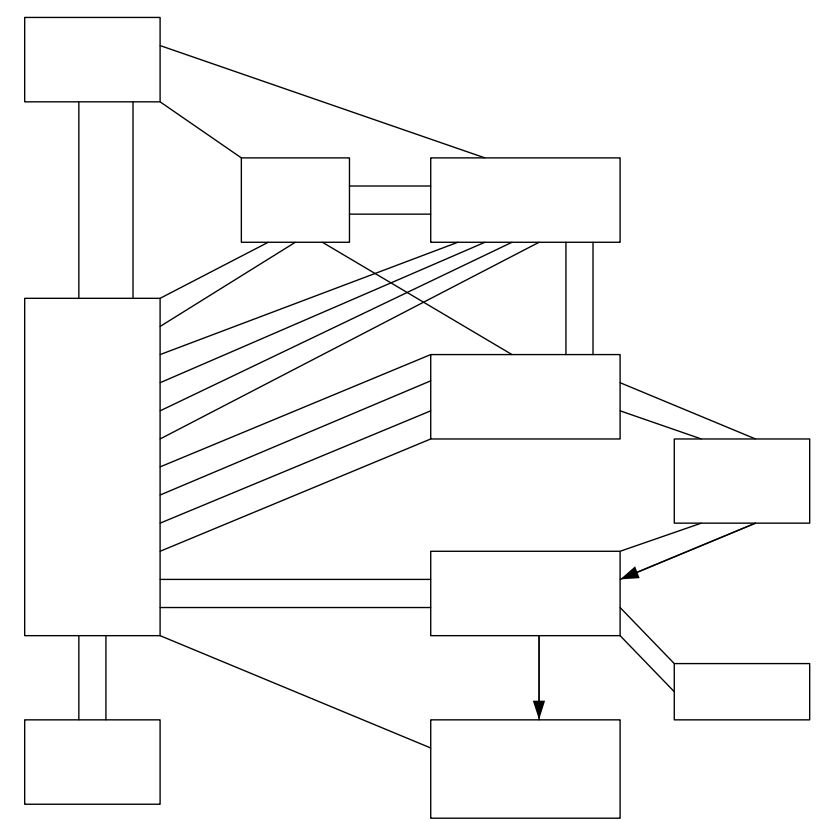

Figure 2. Security partition diagram of Hunan power network.

Table 1. Power balance plan of area A before adjustments.

\begin{tabular}{ccccc}
\hline Generation & $\begin{array}{c}\text { Total } \\
\text { load }\end{array}$ & $\begin{array}{c}\text { Contact line } \\
\text { Group1 } \\
\text { Upper limit }\end{array}$ & $\begin{array}{c}\text { Contact line } \\
\text { Group 2 } \\
\text { Upper limit }\end{array}$ & $\begin{array}{c}\text { Contact line } \\
\text { Group 3 } \\
\text { Upper limit }\end{array}$ \\
\hline 18.92 & 10.31 & 2.75 & 2.47 & 2.23 \\
\hline
\end{tabular}


Table 2. Power balance plan of area A after adjustments.

\begin{tabular}{ccccc}
\hline Generation & $\begin{array}{c}\text { Total } \\
\text { load }\end{array}$ & $\begin{array}{c}\text { Contact line } \\
\text { Group 1 } \\
\text { Upper limit }\end{array}$ & $\begin{array}{c}\text { Contact line } \\
\text { Group 2 Upper } \\
\text { limit }\end{array}$ & $\begin{array}{c}\text { Contact line } \\
\text { Group 3 } \\
\text { Upper limit }\end{array}$ \\
\hline 17.76 & 10.31 & 2.75 & 2.47 & 2.23 \\
\hline
\end{tabular}

Judging from the actual operation situation of the grid, the revised electricity plans have strong operational quality, which guarantees the safe and reliable operation of the grid with the high opinions of operating personnel alike.

\section{Conclusions}

Middle-long term security checking is the key problem about energy generation scheduling. This paper describes the functions, features and its major processes of alternative power trading, and on this basis puts forward mathematical models and algorithms about electricity safety checking of partition. Hunan grid's application examples show that the proposed algorithms can provide important criterions for power trading plans, and are essential to maintain open, fair, equitable principles of the alternative power generation electricity market, to ensure safe operation of power grid.

\section{REFERENCES}

[1] H. Q. Zhang, Y. J. Chang, D. Y. Tang, S. Y. Wang, Q. Chen, Z. G. Li, Y. Q. Wang and J. L. Yu, "A Monthly Electric Energy Plan Making Method of Thermal Power Generation Unit in Energy-saving Generation Dispatching Mode,” Dianli Xitong Baohu yu Kongzhi/Power System Protection and Control, Vol. 39, No. 4, 2011, pp. 84-89.

[2] L. L. Li, Y. B. Guan, J. Geng, J. G. Yao and G. Wang, "Modeling and Solving for Monthly Security Constrained Unit Commitment Problem," Dianli Xitong Zidonghua/Automation of Electric Power Systems, Vol. 35, No. 12, 2011, pp. 27-31.

[3] E. Ni, P. B. Luh and S. Rourke, "Optimal Integrated Generation Bidding and Scheduling with Risk Management Under a Deregulated Power Market,” IEEE Transactions on Power Systems, Vol. 19, No. 1, 2004, pp. 600-609. doi:10.1109/TPWRS.2003.818695

[4] A. Sankarasubramanian, U. Lall, N. Devineni and S. Espinueva, "The Role of Monthly Updated Climate Forecasts in Improving Intraseasonal Water Allocation,” Journal of Applied Meteorology and Climatology, Vol. 48, No. 7, 2009, pp. 1464-1482. doi:10.1175/2009JAMC2122.1

[5] E. Muneender and D. Kumar, "Optimal Rescheduling of Real and Reactive Powers of Generators for Zonal Congestion Management Based on FDR PSO,” 2009 Transmission \& Distribution Conference \& Exposition: Asia and Pacific (T\&D Asia 2009), 2009, p. 6. 